\title{
Advances In Asthma Care: Asthma Educator Certification
}

\author{
Chris Garvey \\ California Thoracic Society, American Lung Association of California
}

\begin{abstract}
Asthma rates in the US have risen during the past 25 years, as have asthma-related morbidity and healthcare costs. Professional organizations involved in asthma care have identified the need to assure that an advanced level of asthma knowledge and skill is available to patients with asthma, their families, and insurers. This need led to development of the certification for asthma educators. The Certified Asthma Educator (AE-C) must meet specific clinical criteria and pass a standardized examination designed to evaluate knowledge and skill for providing competent asthma education and coordination. The development and current status of the Certified Asthma Educator examination process and content are discussed, as are goals of the certification.
\end{abstract}

(C) 2003 Californian Journal of Health Promotion. All rights reserved.

Keywords: asthma, asthma certification, American Lung Association, Certified Asthma Educator

\section{Introduction}

Asthma rates in the US have been rising during the past 25 years, with approximately 14.6 million persons (more than five percent of the population) reporting asthma during the previous 12 months, a 74 percent increase of self-reported asthma prevalence between 1980 to 1996 (CDC \& P, 2002). Emergency department visit rates for asthma between 1992 and 1999 increased 29 percent, with rates for blacks more than three times the rates for whites, and youngest children consistently having the highest rates (CDC \& $\mathrm{P}$, 2002). The cornerstone for modern asthma care in the US was established in 1991 with the development and publication of The National Institutes of Health's National Asthma Education and Prevention Program (NAEPP) with the intent to "bridge the gap between current knowledge and practice." The guidelines were updated in 1997 (NIH, 1997a) and again in 2002 (NIH, 1997b), and include four key components of effective asthma management:

- Measures of assessment and monitoring.

- Control of factors contributing to asthma severity.

- Optimal pharmacologic therapy.

- Education for a partnership in asthma care.
Professional organizations involved in asthma care have identified the need to assure that an advanced level of asthma knowledge and skill is available to patients with asthma, their families, and insurers. This need led to development of the certification for asthma educators. The Certified Asthma Educator (AE-C) must meet specific clinical criteria and pass a standardized examination designed to evaluate knowledge and skill for providing competent asthma education and coordination.

\section{What is an Asthma Educator?}

An asthma educator is a professional who provides skilled assessment, teaching, education and counseling to persons with asthma and their families, enabling understanding and practice of asthma self-management skills. Persons in this role must possess advanced knowledge in asthma pathophysiology, management strategies, cultural aspects of care, developmental and learning theories, and chronic illness models. Skills include accurate and detailed patient assessment and evaluation used for diagnosis of asthma and skillful communication with the patient, family and others involved in the patient's care. The asthma educator engages the patient in a variety of relevant issues and concerns, with a focus on asthma self- 
management strategies. Skills include collaboration with the patient and family, clinicians and providers in development and ongoing provision of the individualized plan of care. Outcome assessment is used to evaluate the effectiveness of care. Finally, the asthma educator is a resource to clinicians and the community.

\section{The National Asthma Education Certification Board (NAECB)}

Background work toward a national asthma certification in the US began in 1999, with representatives from organizations including the American Lung Association, American Association for Respiratory Care, American College of Chest Physicians, American College of Allergy, Asthma \& Immunology and American Academy of Allergy, Asthma and Immunology and the Association of Asthma Educators identifying the need for an asthma educator certification process. The process developed into the National Asthma Education Certification Board, Inc. (NAECB), founded in 2001, with stakeholders of involved organizations electing the first volunteer Board of Directors. The Board includes 17 members representing asthma education, including allergy/immunology, behavioral science, emergency medicine, nursing, patient advocacy, environmental health, health education, medicine, pediatrics, pharmacy, public health, pulmonary and respiratory therapy. The NAECB is a non-profit organization with a mission "to promote optimal asthma management and quality of life among individuals with asthma, their families and communities by advancing excellence in asthma education through the Certified Asthma Educator process."

An additional goal of the NAECB is to link insurance payment for asthma counseling by the Centers for Medicare \& Medicaid Services (CMS, formerly HCFA) by 2003. According to Linda Ford, MD, the first chair of the NAECB, CPT codes are in place for use by asthma educators, which have been used and reimbursed on a limited basis. Some of the codes were originally used for behavioral modification services. Providers using these billing codes should be prepared to provide insurance carriers with supportive information regarding thorough patient evaluation including assessment of patient knowledge, intervention and evaluation of the intervention. An assessment code is available, and other codes are used for interventions. The codes are billed at 15 minutes per unit for the total amount of time spent providing direct care to the patient. Current CMS rates for these temporary codes are $\$ 28$ per unit. Temporary codes are commonly used by CMS to evaluate usage and costs of services.

Outcome studies to evaluate the effectiveness of education by a Certified Asthma Educator are in the planning stages to assess the benefit of this process and to help guide the re-certification process.

\section{Examination Information}

The NAECB Examination is a computerized test offered at more than 100 testing centers nationally (Table 1). Persons eligible for certification include licensed or credentialed health care professionals or individuals providing a minimum of 1000 hours of asthma education, counseling and / or coordination services. Applications may be submitted online or submitted in paper format to the NAECB Examination (Table 1), Applied Measurement Professionals, Inc., 8310 Nieman Road, Lenexa, KS 66214-1579; Phone: (913) 541-0400. The examination fee is $\$ 275$. If needed, a repeat examination costs $\$ 150$. Re-certification is required every five years and costs $\$ 275$. The NAECB receives approximately 75 applications per month.

\section{Examination Content}

The examination consists of 175 questions (150 scored questions and 25 pre-test questions). The examination measures knowledge of asthma pathophysiology, factors contributing to acute and chronic asthma, patient and family assessment (history and physical examination, objective measures, educational needs) management (medication and delivery devices, behavioral and environmental modifications, development, implementation and evaluation of the asthma management plan) and organizational 
issues (program outcomes, referral and professional networking). Various organizations have offered preparation courses, and plan additional courses in the future, including The American Association of Respiratory Care and various local American Lung Association offices in the US.

\section{The Author's Experience in the Certification Process}

The completion of the online exam application and the computerized examination were clear and easy to follow. I prepared for the exam by reviewing the NIH asthma guidelines and relied as well on 27 years of experience providing care and education for persons with asthma, and writing clinical publications on asthma. The only surprise for me regarding the content of the examination was a great emphasis on knowledge and recall of interpretation of peak expiratory flow or forced expiratory volume in one-second variability levels associated with specific step levels of asthma severity. I personally walked away not sure I had passed the exam (which I had). I think if I had taken a preparatory course, I would have better anticipated the exam content and perhaps have been more confident in the outcome of the exam.

The Association of Asthma Educators has played an important role in development of asthma certification examination and has an informative newsletter and annual conference for persons involved in asthma education and care. Their URL is listed below in Table 1, along with other online resources and links.

The Asthma Educator Certification process will serve patients with asthma, their families, insurers and the community by identifying competent providers of advanced asthma assessment, education, and coordination of asthma services.

Table 1

Links to Online Resources

\begin{tabular}{|c|l|}
\hline \multicolumn{1}{|c|}{ Online Resource } & \multicolumn{1}{c|}{ Web Address } \\
\hline Association of Asthma Educators & \\
\hline & $\underline{\text { http://www.asthmaeducators.org/ }}$ \\
\hline Frequently Asked Questions about the Exam & $\underline{\text { http://www.naecb.org/exam_info.FAQ.htm }}$ \\
\hline Test Application & $\underline{\text { http://www.naecb.com/pdf/application.pdf }}$ \\
\hline Candidate Handbook & $\underline{\text { http://www.naecb.com/pdf/NAECB Handbook_AE-C.pdf }}$ \\
\hline Exam Testing Categories & $\underline{\text { http://www.naecb.com/pdf/exammatrix.pdf }}$ \\
\hline Find An Assessment Center & $\underline{\text { http://www.goamp.com/info/aspen_tc web.Pick_Exam }}$ \\
\hline How Exam is Scored & $\underline{\text { http://www.naecb.org/pdf/passing_score.pdf }}$ \\
\hline
\end{tabular}

\section{References}

CDC \& P. (2002). Surveillance for asthma -- United States, MMWR Surveillance Summaries March 29, 2002 / 51(SS01);1-13. Retrieved February 11, 2003, from http://www.cdc.gov/mmwr/preview/mmwrhtml/ss5101a1.htm

Applied Measurement Professionals, Inc.. (2002). NAECB examination registration online. Retrieved February 11, 2003, from http://www.goamp.com/sched/aspen web applications.choose client?p client code=

National Institutes of Health. (1997). National asthma education and prevention program. Expert panel report 2: Guidelines for the diagnosis and management of asthma. Bethesda, MD: National Institutes of Health, National Heart, Lung and Blood Institute. US Dept. of Health and Human Services Publication No. 97-4051. 
National Institutes of Health. (1997). National asthma education and prevention program guidelines for the diagnosis and management of asthma-update on selected topics 2002. Bethesda, MD: National Institutes of Health, National Heart, Lung and Blood Institute; 1997. US Dept. of Health and Human Services Publication No. 02-5075.

\section{Acknowledgements}

This article was submitted on behalf of the California Thoracic Society, the medical section of the American Lung Association of California (http://www.californialung.org).

$\underline{\text { Author Information }}$

Chris Garvey, RN, MSN, MPA, FNP, AE-C

California Thoracic Society

American Lung Association of California

\section{Asthma and Lung Disease Research Fund on the California Income Tax Form}

http://www.californialung.org/research/fund.html 